\title{
TAMALES PARA LA EMBAJADA
}

\author{
TAMALES FOR THE EMBASSY
}

\author{
Carlos Navarrete Cáceres*
}

DOI: http://dx.doi.org/10.29043/liminar.v19i2.853

\section{A las cocineras guatemaltecas que en el exilio nos dieron sabor de patria.}

$\mathrm{N}$ o tocaron la puerta, la echaron abajo a culatazos y patadas, atravesaron el cuarto de las patojas y se metieron directamente al nuestro, como si ya supieran en donde dormíamos. Ni tiempo le dieron de sacar el revólver y creo que tampoco lo hubiera hecho para no perjudicarnos, porque nos habrían matado a todas. A rastras se lo llevaron sin dejar de golpearlo. A mí me empujaron a un rincón y ni abrazarlo pude. Desde esa noche no supimos más de él. Mejor lo hubieran matado, no tendríamos esa tremenda duda.

No se imaginan la angustia. Durante semanas fue correr de cuartel en cuartel, preguntándole a los policías como si cada uno de ellos supiera. Puras esperas junto a otras familias, malos tratos y desprecio. Un que licenciado me dijo que dejara de joder, que los subversivos no tenían cara y por eso no tenían por qué aparecer. Los poquitos parientes que se atrevieron a asomarse me aconsejaron que nos cambiáramos de rumbo y caímos en una casita prestada por una cuñada con la que congeniábamos. La única que dio la cara.

* Carlos Navarrete Cáceres. Doctor en Antropología por la Universidad Nacional Autónoma de México. Profesor-investigador en el Instituto de Investigaciones Antropológicas de la Universidad Nacional Autónoma de México. Temas de especialización: arqueología de tierras altas del área
Desde entonces me encerré con mis hijas. La estancita constaba de un cuarto algo grande y una cocina mediana, suficiente para cambiar de aquel ambiente en el que se quedaron colgando los ruidos, los ladridos del chucho y los gritos. En ninguna parte me daban trabajo y mis hijas dejaron la escuela. Desde que con otras esposas y madres firmamos una carta pidiendo por los desaparecidos nos empezaron a seguir. Paraban el carro frente a la casa y luego en las noches se quedaban dos orejas vigilando, ¿vigilando qué, si nadie entraba ni salía y nadie nos visitaba?

Parecíamos monjas rumiando soledad y negrura, retrato del luto que me impuse. Malditos, malditos, me decía hablando sola, malditos, y si daban noticias de que habían matado policías y soldados me entraba rabia de pura alegría y hasta pateaba como queriendo machucarlos. Sí, sí, gruñía, pataleando como si el gusto fuera real. Mis hijas solo mirando.

La noche que las noticias dijeron que los subversivos habían ametrallado al general Cansino, el chafarote que asesinó a Memito Colón, me puse a carcajear pero sollozando, me alboroté el pelo de tamaña felicidad y escupí sin saliva. Mis hijas corrieron a abrazarme asustadas, cálmate mamita, ya pensá en otra cosa, acordate

maya: Chiapas, Guatemala; Mesoamérica, etnoarqueología. Correo electrónico: chicapons@hotmail.com.

Recibido: 11 de septiembre de 2020 
que nos tenés, no podemos seguir como estamos, mejor vonós... Exhausta, como saliendo de un baño caliente, de muy adentro me salió decirme: Tengo que ganar la calle y vivir por ellas, repitiéndomelo y repitiéndolo hasta rendirme el sueño.

A la mañana siguiente me levanté más temprano. Desperté a las patojas: vístanse que nos vamos al mercado y no hagamos caso de esos hijos de la gran puta que están enfrente. Con tres canastos salimos porque me brincaba una idea.

Del ahorro quedaba poco pero no me eché pa'tras. A medida queíbamos comprando y tratando con las doñas del mercado comenzamos a reír como no lo habíamos hecho en semanas. Hasta chapas les salieron a mis hijas.

Al extender las compras en la mesa la casa agarró brillo, y al ver las hojas de maxán y la harina sentí que me estaba armando contra el infierno. Me noté extraña canturriando, tanto que las hijas pusieron un disquito con piezas viejas que guardábamos. Un tesoro, pues. En un extremo puse la masa blanquísima y la carne de coche en pedacitos bien lavados; saqué las aceitunas y corté tiritas de chile colorado...

Me salvó un viejo cuaderno de cocina deshojado que mi mamá heredó de la abuelita, cocinera de casas de pomada en tiempos de don Manuel. Una receta en cada hoja, en letra pendoleada. Receta de cinco clases de tamales, según el apunte. Algunas navidades había ayudado a mi mamá a hacer los tamales familiares, así que me acordaba y con las señas del recetario puse manos a la obra. Esta vez hice solo veinticinco, apartamos tres para nosotras y metí los restantes en dos ollas para ir a regalarlos con los vecinos. A regalarlos, así fue la idea que me nació a ver si hacíamos clientela.

Salimos y los chontes sorprendidos, como queriendo averiguar qué llevábamos, pero no se movieron. Uno de ellos nos siguió a distancia. Nada sospechoso había en tocar en algunas casas y sacar un tamal de muestra para que probaran y si les gustaba que regaran la voz. Receta antigua, les decíamos. A la semana comenzaron los primeros toquidos y los clientes a encargar. Al principio tímidos por los tales orejas que todo lo apuntaban, y luego ya sin miedo con tal de comer de mis tamales. Que milagro ni que el Señor Dios dejó que desaparecieran a mi maridito, el compa, como gustaba que le dijeran. El milagro fueron las ganas de vivir que me contagiaron las hijas.

La oportunidad de ganar la calle brotó una tarde al regresar. En la esquina uno de los policías me dijo buenas tardes y aunque caminé más aprisa no dejé de inclinar un poquito la cabeza. A las dos semanas, una noche de lluvia, vi por la ventana a la pareja de policías ateridos de frio en el quicio de una puerta y sin mayores palabras les llevé un termo con nescafé caliente. Ni modo que les llevara del buen café que a veces nos mandaban los vecinos.

Desde esa vez las patojas gozaron de mayor libertad. Salían a comprar sin sentir en la espalda la miradasombra, ni que apuntaran las horas de entrada y de salida, ni sentir en la espalda los ojos lengüeteados de mal deseo. Más mejoró el trato desde que un sábado por la noche con el café les mandé dos tamales.

La clientela prosperó. Venían a hacerme encargos para fiestas y algunas señoras se quedaban a platicar y a tomar café. Con un sobrante compré un poco de pintura para que no vieran el cuarto tan indecente. Comenzamos a ir los miércoles al cine, y dejé que aquellas se quitaran los colores de luto. En menos de dos meses me hice de un radiecito de oportunidad y hasta las oí platicar de regresar a la escuela.

Las cosas seguían horribles en Guate, solo noticias de muertos, de asesinatos y secuestros de personas de las que nunca se volvía a saber. Había cientos de mujeres como yo o peor, a quienes les habían matado toda la familia; viudas o solteras a la fuerza, medio abandonadas por los maridos que del miedo se iban a buscar la vida al norte. Y más peor se puso la situación cuando un general sacó a otro general del palacio. Sí, más peor: general tras general.

A la noche siguiente, al llevarles su cafecito a nuestros policías, nos dijeron que esa sería la última vez que los veríamos porque iban a realizar cambios en el cuerpo y no sabían qué clase de agentes serían los reemplazos. Puede que parezca mentira pero hasta tristeza nos entró. Y así fue, al día siguiente eran otros, unos fachudos malencarados de mala mirada. Se terminó así el cafecito y los tamales. Habíamos comenzado a no salir a vender 
y eran los clientes los que venían, pero pronto fueron bajando de solo ver al par de huevones que se turnaban vigeando a todo el que pasara enfrente y apuntando. Y para más zozobra a la vuelta de la esquina llegó de noche un comando a secuestrar a toda una familia dejando los malditos a un bebé solito. Oyendo su desamparo fue en la madrugada a rescatarlo doña Chanita, una viejita solterona, agria como la gran diabla pero de buen corazón y de ovarios.

Vino luego el gran susto. Dos semanas después, como a las doce de la noche, grandes toquidotes en la puerta. Nada. Luego otros más fuertes. Las tres nos abrazamos. Quién, pregunté. Abra rápido o le botamos la puerta. Yo en camisón, con mis hijas detrás. Medio abrí pero me empujaron. Aquí vive Pavel y lo venimos a buscar, el jefe tiene unos papeles que quiere entregarle. Por Dios, cómo no iban a saber que ya no estaba, que se lo habían llevado meses atrás.

Voltearon todo, abrieron el armario y la cómoda, solo faltó que buscaran en el excusado. Por qué viene a verla tanta gente, preguntaron, lo menos son guerrilleros. Por tamales señor, de eso vivimos. A ver, dijo el carota de jashto, a ver, y fueron abriendo cada tamal. A lo mejor usté es guerrillera como su marido y en los tamales mete mensajes iverdá? iverda? iverda?, mientras revolvían todos los que estaban listos para el sábado. Al irse, el muy cerote pasó diciendo: vea que sus hijas están bonitas, no les vaya a pasar algo por andar de alborotadoras con tamales falsos. Ni qué decirle.

Temprano me habló la vecina. Estamos preocupados, toda la cuadra se enteró, pobrecitas y solas. Dice mi esposo que deberían irse lejos, porqué las van a estar fregando siempre, que es cosa de listas con nombres y aunque no tenga usted que ver con lo que hacía don Pavel para ellos es igual... anda un carro negro con sombrerudos dando vueltas, cosa de meterle miedo al barrio. Y entendí que tenía razón.

En tres días los vecinos ayudaron a vender baratos los chunches. Los pasamos por encima de las bardas que separan los patios de la fila de casas, para que no se dieran cuenta que nos íbamos. No había de otra. Casi lloro cuando se fue la maquinita royal de Pavel en la que escribía cosas que yo no entendía y nunca me quiso decir. Todo, todo se vendió, las ollas para los tamales, el sillón, la cama en que dormían las nenas, hasta las sábanas y las almohadas salieron sin que los orejas se enteraran. Solo los discos de marimba no quise vender y los envolví en trapos. Entre vecinos nos mandaron más de ciento cincuenta chemas, y con el ahorrito que habíamos logrado y solo con unas cuantas mudas nos fuimos saltando paredes hasta dar a una casa con frente a la calle de atrás. Allí nos esperaba un medio primo con quien nos criamos juntos de niños y siempre mantuvimos cariño. Acababa de regresar de México a donde se fue por miedo, porque cuando se embolaba le echaba vivas a Arévalo y Arbenz y ya lo tenían fichado. Di'alpelo el primo, para comenzar se consiguió una fe de nacimiento de mexicano y se puso a practicar el cantadito comiteco y a esforzarse en olvidar las palabras chapinas. Hizo mancuerna con una comercianta chiapaneca y mejoró el negocio contrabandeando por la línea ropa gringa usada y cambiando guaro fino por tequila. México contra Guatemala: uno a uno, decía riendo. Ya medio calvo, canoso, bigotudo y otro nombre, se había venido a Guatemala a montar una bodega de pura fayuca. Teníamos años de no comunicarnos pero nos vino a auxiliar sin importarle tiempo ni riesgos. Afuera tenía un carrito con el que nos llevó a una casa en un barrio humilde, que dijo la estaba comprando. En tres días nos vamos, no salgan.

Al cuarto día vino por nosotras y enfiló por la carretera a occidente, aprovechando que era domingo y había mucho tráfico de paseantes y la revisión de los retenes era rápida. Pasamos el primero sin problemas, sin que nos hicieran abrir la cajuela ni nos bajaran. Dijo que éramos hermanos de papá diferente y como el segundo apellido es el mismo se lo creyeron y a las patojas ni papeles les pidieron. Vamos a una fiesta en La Democracia. Que tengan buen viaje. Almorzamos en Los Encuentros, pasamos otros dos retenes y dejamos Huehue a un lado. En el último se vio que mi primo era bien conocido porque se bajó a saludar y qué tal vos y bromas y a ver si de regreso nos echamos un guaro. Conocidísimo pues.

De veras que había una fiestecita en la casa de ese pueblo caluroso donde bajamos llamado Democracia. 
Una de mis hijas bromeó de que, en vista de tanta sangre derramada por los chafas, el apodo se lo pusieron para babosear a la gente de fuera. No me reí, me asaltó el recuerdo de la puerta rota y de los insultos y patadas de aquellos animales.

Ya nos había dicho el primo que el señor Bartolo no era cargador ni pollero, sino corredor, que no tuviéramos pena que a eso se dedicaba, a guiar a quienes lo contrataban dispuestos a dar el brinco en la frontera, palabras que en mi turbación no entendí. Quedó en claro que tenía trato con los vistas mexicanos de la migra a quienes entregaba mercadería japonesa, igual que con mi primo. Que no tuviéramos pena con el dinero, pues ya todo estaba arreglado con mi pariente y no íbamos a pagar mordidas. Allí estuvimos dos días eternos esperando y mi primo se despidió encargándonos mucho con él. No se preocupe, yo las voy a cuidar. Casita de campesino con su milpa y montón de chiricitos. La verdad es que tanto don Bartolo como su señora se portaron de lo más atentos. Nos prestaron unos catres de lona medios shucos, pero ni modo de despreciar. Frijolitos negros y tortillitas muy sabrosos.

Tempraneando y con niebla salimos por un camino de tierra en un carrito de comerciante para la frontera. En una aldeíta de gente muy pobre con las mujeres de corte, donde lo conocían, dejó don Bartolo el vehículo. Ahora a caminar, dijo, metiéndonos por un extravío barrancoso que bajaba y subía. Esta es la frontera, en adelante van a poder descansar. Como a la hora de cruzar la línea topamos con unos ranchitos regados y entramos en el que hacía de tienda. Aquí van a estar un día más, las voy a dejar en buenas manos, no van con ningún pollero, van con funcionarios de respeto, dijo. Se despidió cariñoso, yo creo que por lo que le había dicho mi primo y lo que le conté yo misma. Cómo les vamos a pagar, le pregunté, venimos estrechas. Ni se preocupen, es negocio entre su familiar y yo, cosa de favores. Va a venir por ustedes un señor de uniforme que las va a encaminar, entra todo en recambio de amistad, no se preocupen.

Los tenderos de la chocita eran poco comunicativos, pues no muy hablaban español. Los sentí guatemaltecos pero no lo decían. Eso sí, sonrientes, y otra vez frijolitos y tortillas, y más que café revolvían tortilla quemada. En dos colchones medio usados dormimos dos días, y aunque ya no sentíamos miedo estaba la incertidumbre de no saber qué venía.

Al mediodía del plazo fijado se presentaron dos uniformados de kaki, con tamañas escuadrotas y banderita mexicana en la manga. No se asusten, dijo el más serio, con la recomendación de su primo basta, favores y negocios corren parejo. Nos dio confianza su decir y notar lo bien que se llevaban con los del ranchito. Los uniformados resultaron ser agentes de la migra.

Al rato nos pidieron que trajéramos nuestros tanates y una maletita y descendimos a pie un buen trecho. El del rancho se acomidió a cargarnos las cositas hasta la carretera en donde estaba la camioneta. Tamaño escudo mexicano con letrero y todo. Nos subieron atrás. Pasamos una caseta, luego un retén grande antes de Comitán y ellos directos, sin detenerse, solo saludaban y cómo les va muchachos y que el sábado nos vemos y jajajá. Medio rudos para tratarse entre ellos, pero con nosotras respetuosos. La única parada del camino fue en un comedor de donde salieron con refrescos y tortas y nos invitaron. La primera cosa rica que probé en la incertidumbre.

En el primer pueblo grande pasaron una como aduana y uno de ellos se bajó y a los quince minutos regresó con un sobre. Era un pase sellado para las tres. Que no tuviéramos pena, que con ese escrito no nos iban a bajar si paraban a revisar el pasaje, los compas ya saben. Al llegar al paradero de autobuses ellos mismos nos compraron los pasajes con un pisto que mi primo les había mandado. Van a ir en autobús de primera, porque en estos transportes solo suben a semblantear a los pasajeros, en cambio en los de segunda viajan indios y guanacos que luego, luego, se dan a conocer. Nos dio un papel con indicaciones de cómo tomar un taxi de los de caseta y con la dirección a donde nos debía llevar; a mi hija mayor le pasó varios billetes de águila y le descambió algunos quetzalitos que le quedaban. Guárdalos en el calzón y no los saques para nada, es para que comiencen. A mí me dio otros en una bolsita con fichas. Es para lo que vayas necesitando en el viaje; al llegar no des limosnas ni ayudas, sácalo de a poco, y 
si preguntas algo hazlo arrecha, que no te vean como gata prestada.

Los nervios comprimidos me sacaron lágrimas de agradecimiento. No me dejó el hombre. Que la amistad con mi primo iba más lejos que los negocios. Vaya con Dios, señora, cuide a sus chamacas tan bonitas. Dijo chamacas como en película mexicana.

Viajamos tranquilas, durmiéndonos por ratos. Pasamos pueblos que se veían grandes y solo en Puebla paramos un rato. En los alrededores se veían comedores, pero tuvimos miedo y solo bajamos rapidito a la tienda de la terminal a comprar unos panes rellenos y un agua de café, que eso era.

Llegamos por fin al Defe, calles y calles de cuando entramos a la ciudad. Púchita con la terminal, enorme y larga, pasillos de no acabar, un piñal de gente apretada cargando valijas y bultos, empujones y ni un disculpe. Nadie ve a nadie, señales por todas partes: siga la flecha, entrada, no es aquí, baños, sala l y 2, ni por dónde. Tan turbada que leí sapo en vez de Tapo. Salimos por un lado y los taxis estaban del otro, pero lo tomamos; no sabíamos de precios y nos babosearon. Por La Merced dijo el chofer.

Calle de las Cruces decía la dirección. Ojalá encuentren lugar porque allí van paisanos con problemas como los tuyos, me había dicho el primo. Tuvimos suerte. Le dijimos a la encargada de parte de quién veníamos y le dimos el papel. Nos pasó a un como departamentito de piezas cuaches y cocinita, enfrente de un gran patio con los baños y el lavadero comunes. Una casona de esas que llaman de vecindad, con doble fila de cuartos y una escalerota a otro piso de puertas enfiladas en donde vivían mexicanos y centroamericanos, todos refugiados. Una familia hondureña comerciaba con ropa usada que el padre don Chentío y su hija salían a vender en una como carretilla con perchas; otro hondureño vivía con una nica dependienta de tienda; un salvadoreño elaboraba sorpresas, unos sobrecitos con dulces y algún juguetito; en un cuarto se apilaban los cipotes, cuatro jóvenes salvadoreños que a saber de qué trabajaban, todos tatuados y medio misteriosos pero con nosotras muy acomedidos; dos beliceñas bien plantadas, dis'que bailarinas, siempre regresaban medio bolas en la madru- gada. Los vecinos de arriba eran más serios: la familia de un velador de fábrica, un tira como le dicen aquí a los orejas, con su mujer y dos hijas, y en un cuartito del fondo un viejito que vendía bolígrafos y llavecitas de madera que él mismo fabricaba con figuras del ratón miguelito y el pato donald. Todos con solidaridad de gente gafa, amolados como dicen aquí, amables desde el primer día, sobre todo un par de estudiantes que pronto congeniaron con mis hijas y les prestaban libros. Solo con una familia casi nadie trataba y no pasábamos del buenos días. Mejor.

Nos fuimos conociendo entre todos. Una familia era evangélica, muy serio el señor pero cordial; él nos fue encaminando en esos días. Vayan a ver al licenciado Capuano, se llama Ernesto, él puede arreglarles sus papeles como hizo con nosotros, no es conveniente estar siempre escondidos e indocumentados, sobre todo si son gente con ganas de trabajar.

A los pocos días él mismo nos llevó con ese gran señor. Que Dios bendiga siempre su alma. Nos recibió de lo más fino, que le contáramos nuestras penas y no me dio vergüenza que se me salieran las lágrimas entre gente igual de jodida como nosotras, guanacos, catrachos, y un como argentino porque hablaba de ché. A unos nos pidió papeles y si no tienen no tengan pena. En piña nos llevó a esa oficina de gobernación muy cerca de su casa. Puchis, todos lo conocían, aquí con uno, aquí con otro, cada caso, cada problema, y todos tenían algo que decir de los militares: al salvadoreño le habían matado a toda su familia, al hondureño lo torturaron, al argentino le desaparecieron a la esposa y él apenas logró escaparse con la hija. Así todos. A cada uno le fue abriendo su carpeta y para comenzar nos dieron tres meses de gracia.

Fue toda una semana de escritorios y ventanillas, pero me logró documentar el permiso de trabajo familiar por cuestiones humanitarias. Gracias, gracias, licenciado, no sabe lo agradecidas, pero no tenemos con qué pagarle, le dije más que apenada. Nada, me contestó, nada; somos todos paisanos y para eso estamos los comunistas, para dar apoyo. Habló de camaradas y no sé cómo me sentí, si conmovida u orgullosa porque desde mi marido no había vuelto a oír esa palabra. 
Esas semanas sirvieron para que el pensamiento volara sin detenerse en nada, como si las oficinas frías $y$ ver tanto encorbatado no diera chance de sentirse viva, de asegurar lo que nunca acaba de ser cierto. La tristeza se me dio peor, se hizo desasosiego, el tener que presentarnos cada mes en migración para contestar lo mismo: que si seguíamos viviendo en la misma dirección, que si estábamos trabajando y en dónde, y exigencia de presentar cartas de recomendación sin conocer a nadie que te las diera, filas y filas de gente extranjera esperando, y advertencias y prohibiciones como si cargáramos shuquera...

Ciudad hostil, tiendas de colores diferentes, otro olor y sobre todo los sabores. Si no aprendo a saborear tampoco voy a poder hacer nuevas amistades, pensaba, intentando poner cara alegre ante el mole negro tan recargado o cuando ofrecían nopalitos. Por eso busqué cobijo con los paisanos, pero al cabo de dos meses me sofocaban las mismas conversaciones, las eternas comparaciones: que si las empanadas y los frijoles volteados... que si los aguacates de allá son más sabrosos... y las esperanzas y las mentiras que nos inventábamos de que ahora sí las guerrillas van a mandar a la chingada a esa bola de cerotes milicos.

Nunca estuve tan abajo, sin suelo propio para seguir mi sombra, sin ni siquiera un calendario con el lago de Atitlán. No es asunto de visiones sino de la realidad que no es. Me sentaba sin estar cansada y me salía a la esquina solo para devolverme. Mis hijas me animaban a salir, a ir al cine. Lo intenté, pero no veía la lica y acababa por no entender de qué trataba, de qué se reían o gritaban, deseando que encendieran las luces para regresar.

Una hondureña que se dedicaba a asear casas le habló a una de las patojas para que le ayudara y así comenzamos a tener para el diario. La otra tuvo suerte, la recomendaron con un abogadito que asistía a los comerciantes de un mercado sobre ruedas y la tomó de su secretaria. Hasta como mexicanas comenzaron a hablar. Por mí hubiera seguido durmiendo en el suelo, pero ellas comenzaron a ajuerar los cuartos; compraron la mesita y cuatro sillas de pino, luego dos camas y el abogadito le regaló a mi hija un armario viejo, suficiente para lo que teníamos. Luego una tele de segunda. No fueron los programas, fui yo la que se metió en ella.

Mis hijas se iban adaptando, hicieron migas con los jovencitos de la vecindad y comenzaron a pedirme permiso para ir al cine o a alguna fiesta. Jóvenes, pues. Siempre decía que no, para luego decir sí. Luego agarré la manía de verme a cada rato en el espejo y la última vez noté las arrugas, las ojeras y el color verde. Saqué la lengua y comprendí: si te mantenés inútil no vas a salir del hoyo, le estás robando alegría y futuro a tus hijas. Sos un valladar de negrura, dejalas que pongan música, que repasen sus pasitos y no te resguardés en el cuarto a ver telenovelas para perderte detrás de las figuras. Así pasaron tres meses y de repente me salió pensar en los tamales.

La vecina salvadoreña ofreció prestarme una olla grande y con una de las patojas me fui al mercado de La Merced a buscar lo necesario. Que cosa: al cruzar de cuadra en cuadra se me fue devolviendo el alma, como convaleciendo de una larga enfermedad. En ese mercado se consigue de todo, y no fue difícil aperarnos de los ingredientes que empleamos en Guate o de sus equivalentes mexicanos pues lo único que cambian son los nombres. Se rieron cuando pregunté por el precio de la carne de coche. Nada de maxán o de cibaque, ni chile guaque que aquí es pimiento, o las semillas de calabaza que llamamos pepitoria, y ni hablar en la jerigonza de que el tomate es jitomate y el miltomate es tomate o del salpor que no encontré. Con palabras iguales o diferentes llenamos dos canastos, aparte de los atados de hojas de plátano.

Los tamales no son cosa de revolver masa y envolverla, menos para quien siente que en cada bola da un paso, ya de sobrevivencia, ya de esperanza. Lo vemos con las tortilleras que del comal hacen parte de su cuerpo. El sudor del trabajo es sangre pura, decía mi abuelo: tratá de robarle su piedra de moler a una india y verás la morongueada que te sacás.

Manos limpias y paletas de madera, todo bien medido en onzas y libras, porque eso de los kilos nunca lo he entendido. Limpia la carne de coche o de chompipe, bien cortadita en cubos y sobada con sal; ordenados y lavados los tomates maduros haciéndole juego a los 
chiles: de lata los pimientos color de avergonzada, dulces los zambos, de olor espeso el de pasa, dos guaques amarillos frescos, muy verdes los miltomates y la cabeza de cebolla sin tela. Todo ordenado sobre la mesa bien lavada para que la combinación se vaya adecuando. Lo que es la nostalgia: cuando cortaba las cebollas me di cuenta de que no lloraba por el zumo sino de recordar, porque a partir de la primera vez que los cociné puse mis dos discos de marimba para sentir como cuando Pavel me sacaba a bailar. Al diluir la masa con agua para evitar los bodoques seguí el compás dando mis pasitos y canturreando, moviéndola despacio para asentarla sin que se pegue a la olla. Un sonecito y la porción de manteca, Luna de Xelajú y a calcular la sal, luego una marcha de cuando niña y los desfiles hasta cuercerla no muy dura; vuelta de disco y a reposarla. La carne no se enfría y la música tampoco. Calientes la lumbre y los boleros, y el sartén con la manteca y el recado chirriando como repique del Ferrocarril de los Altos.

Mi abuelita decía que cuando las hojas están despuntadas, listas para recibir su paletada de masa, hay que invocar al Señor para que la mano no pierda la sabiduría de las porciones: solo una aceituna y no dos, su tirita de chile pimiento y no más para que el paladar tenga sorpresas. Al cortar las porciones de carne, la buena tamalera sabe que el pedacito, aunque tenga hueso, debe dejarle a la boca la sensación de querer más. La sazón correcta equilibra masa, recado, carne y sabor, como si fueran letras de canción.

No sé, pero la tristeza bonita me llegaba cuando poníamos el recado y lo demás en medio de la masa y doblábamos las hojas. Qué le pasa, mamá, por qué esos pucheros, me decía la patoja que me ayudaba, estás soltando lágrimas y sonrisas. Era todo junto, sentirme ajena y al mismo tiempo prendida al pasado que se borraba y en cada tamal volvía, quizá porque al envolverlos se van sumando finales, sobre todo al anudar el trozo de cibaque y no saber al gusto de quién van a ir a parar. Al que come un buen tamal se le van los malos humores, decía la abuela cuando le ponía sal y su pisquita de azúcar al agua para cocerlos, y decí un Padre Nuestro pero no completo, detenete en el pan nuestro de cada día y repetido tres veces para que salgan bien.
Los primeros veinte los regalamos entre paisanos del exilio para que regaran la voz. Al licenciado Capuano le llevé dos por lo bondadoso de estar arreglando nuestra estancia en ese lugar tan sin alma y cada mes le llevaba un su par. A todos les pasamos el teléfono de la portera, para que el que quisiera encargar lo hiciera antes de media semana y lo fuera a recoger el sábado después de las doce.

Por pláticas entre familias empezaron a llover los clientes, primero chapines, luego salvadoreños y después de toda condición. Ni abasto nos dábamos. Tuve que comprar una gran tina de lámina para que cupieran. Primero despachábamos en la casa, pero a medida que la clientela aumentó los citábamos en una esquina del Hospital Juárez, calle ancha para facilitar la entrega a los que llegaban en carro. Como a las cuatro de la tarde terminábamos de vaciar las tres ollotas. De eso vivimos desde entonces, de lo que las patojas ganan y del empeño que les ponemos a los tamales de miércoles al sábado.

En la noche, terminada la repartición, al regresar con las ollas vacías sentía que el pecho se me hundía porque la soledad oprime. Solo me quedaba esperar la llegada del miércoles para recomenzar el alivio de la tarea.

Cómo no estar agradecida de los tamales, si también me brindaron la oportunidad del desquite. Que te llaman de la Embajada, me gritó la portera desde el patio.

¿De la Embajada...? Se habrá muerto alguien, porque nunca vinieron de allí buenas noticias, y me fui al cuarto de la portera a contestar. En el acento noté la tiesura de que era chafarote quien hablaba.

Doña Merci mucho gusto soy el agregado militar de la embajada de Guatemala para informarle que el jefe de las fuerzas armadas ha dado la orden oficial de que este año le corresponda al cuerpo militar financiar los tamales para la celebración del quince de septiembre mi molestia nace de la fama de que en sus manos nacen los tamales más sabrosos y por lo tanto en nombre de nuestra delegación tengo el gusto de solicitar sus apreciables servicios para que nos surta una dotación de trescientos tamales colorados para la ceremonia del mes próximo en el entendido que respetamos los costos que actualmente cobra pagándosele de adelanto las tres cuartas partes y el resto en el momento de la entregael señor embajador desea conocerla y con la dirección suya que tenemos le está enviando una invitación... 
Volví a la vida que se me desprendió desde la noche aquella de los gritos al decirle que sí, que estaba dispuesta. No sabe qué alegría poderlos atender, pero con la condición de no cobrar, que se los voy a hacer gratis. Señora, qué gran patriotismo el suyo... comenzó a decirme. Nomás que no los voy a hacer con recado sino de mierda, le dije.

Esperé tantito para escuchar su cara y colgué.

\section{Glosario y notas aclaratorias}

Arévalo y Arbenz: doctor Juan José Arévalo y coronel Jacobo Arbenz Guzmán, presidentes de la república entre 1944-1954, tiempo calificado por Luis Cardoza y Aragón como los "Diez años de primavera en el país de la eterna tiranía”. Década de las mayores transformaciones sociales y culturales en la historia de Guatemala. El Departamento de Estado Norteamericano, la añeja oligarquía y el peor conservadurismo nacional frustraron el proceso.

Arrecha: decidida, atrevida, valiente, audaz.

Bola: borracha, de embolarse: embriagarse.

Cargador: guía que traslada indocumentados a través de la frontera por tramos cortos.

Carne de coche: carne de cerdo, cuche, cuchí, chancho, en términos centroamericanos.

Casas de pomada: de gente rica, acomodada.

Catracho: hondureño, término popular centroamericano.

Cerote: excremento; se emplea como insulto o despectivo.

Chafas: militares; el nombre viene de un tipo de espada, distintivo hasta 1954 del uniforme de los oficiales guatemaltecos.

Chapines/chapinas: nombre que se da a los guatemaltecos en Centroamérica.

Chemas: billetes de 20 quetzales con el rostro del general José María Orellana, quien durante su presidencia reformó la moneda guatemalteca.

Chirices: niños pequeños.

Chompipe: pavo, guajolote en México.

Chontes: policías. Otros nombres: polacos, tiras, orejas (de la policía judicial o "secreta"), guaruras (mexicanismo para guardaespaldas o custodios, difundido por la televisión y el cine).

Chucho: perro. Se le dice a quien es voraz.

Chunches: cosas domésticas, comunes.

Cibaque: los tallos secos de esta planta se utilizan para

amarrar las hojas que envuelven los tamales.

Cipote: salvadoreñismo para niño.

Comiteco: oriundo de Comitán, Chiapas.

Corredor: el que guía migrantes a través de la frontera para entregarlos a un pollero o traficante de personas.

Corte: tela indígena que se usa en vez de falda, de ahí el despectivo racista "india envuelta".

Cuecerla: cocerla, de cocinar.

Di'alpelo: de al pelo: valeroso, atrevido, solidario, de buen talante.

Defe: Distrito Federal, hoy Ciudad de México.

De pomada: persona de clase alta, pudiente.

Don Manuel: licenciado Manuel Estrada Cabrera, dictador que gobernó Guatemala durante 22 años. Figura central de la novela El Señor Presidente de Miguel Ángel Asturias.

Extravío: Camino corto por lo general abrupto, no reconocido, que acorta rutas largas; sendero de contrabandistas: "Paso de Las Escaleras/íbamos por extravío...”.

Ernesto Capuano: abogado guatemalteco, comunista, exiliado en México durante los catorce años -1931-1944 - de la dictadura del general Jorge Ubico; participó en la comisión gubernamental que redactó el Decreto 900 que promulgó la ley de la Reforma Agraria durante el gobierno democrático del presidente Jacobo Arbenz. A la caída de este se exilió nuevamente en México, dedicándose hasta el final de sus días a gestionar ante la Secretaría de Gobernación la permanencia de los emigrados políticos latinoamericanos, sin cobrar honorarios.

Fayuca: mercancía de contrabando.

Fayuqueando: contrabandeando.

Gafa: sin dinero, pobre.

Guanacos: salvadoreños, término popular centroamericano. 
Guaque: especie de chile.

Guaro: aguardiente de caña, licor en general.

Guate: diminutivo de Guatemala.

Huehue: diminutivo de la cabecera departamental de Huehuetenango.

Jashto: despectivo de indio, corriente, vulgar.

Letra pendoleada: letra manuscrita, cursiva.

Lica: de película cinematográfica.

Machucarlos: de machucar, aplastar, majar.

Manuel Colón Argueta: dirigente estudiantil en la Universidad de San Carlos, destacado abogado, líder político de pensamiento y acción democrática, alcalde de la Ciudad de Guatemala; máximo dirigente del Frente Unido de la Revolución (FUR), partido cercano a la Social Democracia; soportó con dignidad la presión de los regímenes militares, perfilándose como candidato de gran popularidad a la presidencia de la República; en 1979 fue asesinado en una operación dirigida por el general David Cansino, jefe del Estado Mayor del Ejército, quien, al poco tiempo, fue ajusticiado por un comando del Ejército Guerrillero de los Pobres.

Maxan: planta de tallos que brotan individualmente separados, las hojas anchas se usan para envolver los tamales.
Migra: agentes de migración.

Morongueada: golpiza.

Nica: nicaragüense.

Orejas: policías judiciales, de la "secreta".

Patojas(os): niñas, niños, adolescentes.

Piña: aglomeración, sinónimo de muchos.

Piñal: montón de gente.

Pisto: dinero.

Pollero: traficante de indocumentados, opera en red, y es quien los provee de casa de seguridad y transporte.

Púchica o Puchis: exclamación derivada de iPuta!

Salpor: harina fina de maíz.

Shucos: sucios, antihigiénicos, tramposos.

Tapo: Terminal de Autobuses de Pasajeros de Oriente en la Ciudad de México.

Tanates: bultos de ropa y telas, carga en "sábana maletera".

"Un general que sacó a otro general del palacio": se refiere al golpe de Estado del general Efraín Ríos Montt al general Lucas García; pasarán a la historia de Guatemala como gobernantes represivos y genocidas.

Vigeando: vigilando, viendo.

Zambos: especie de chile. 